\title{
Oportunidade Perdida?
}

\author{
Luiz Martins de Melo ${ }^{1}$
}

\begin{abstract}
RESUMO
O objetivo do artigo é analisar os megaeventos esportivos como um produto do neoliberalismo. Essa visão hegemônica internacionalmente desconsidera as diferenças históricas na constituição do sistema capitalista. A construção dos espaços urbanos não são vistos como um parte constitutiva do desenvolvimento desigual do capitalismo como sistema mundial. O caráter monopolístico da Federação Internacional de Futebol Associado - FIFA e do Comitê Olímpico Internacional - COI reforça a inadequação desses megaeventos concebidos para o processo de urbanização dos países desenvolvidos. Isso faz com que o legado desses megaeventos reforce as condições de desigualdade urbana existente.
\end{abstract}

Palavras-chave: acumulação capitalista; megaeventos; desenvolvimento urbano; Brasil; Rio de Janeiro.

\begin{abstract}
The aim of this paper is to analyze the mega events as a product of the neoliberalism. That hegemonic view disregards internationally historical differences in the constitution of the capitalist system. The construction of urban spaces have not been seen as a constitutive part of the uneven development of capitalism as a world system. The monopolistic character of the International Federation of Football Association - FIFA and the International Olympic Committee - IOC reinforces the inadequacy of these mega events designed to the urbanization process in developed countries. This makes the legacy of these mega events to reinforce the existing urban conditions of inequality.
\end{abstract}

Key-words: Capitalist accumulation; megaevents; urban development; Brazil; Rio de Janeiro

\section{Introdução}

A hegemonia do pensamento neoliberal não teve impacto somente na economia, na política e na nova configuração geopolítica mundial. Ela produziu, também, uma enorme mudança na urbanização, fazendo com que grandes cidades e regiões

\footnotetext{
${ }^{1}$ Instituto de Economia da Universidade Federal do Rio de Janeiro- IE/UFRJ.
} 
metropolitanas sofressem uma transformação importante na estruturação dos serviços públicos universais que são o centro dos direitos de cidadania e da democracia.

A construção teórica do pensamento liberal tem sua origem no grupo do Mont Pélérin sob o comando de Friedrich Hayek. A primeira aplicação das suas orientações de política pública foi feita na ditadura chilena a partir de 1973. Mas a experiência chilena não poderia servir de padrão para a conquista da hegemonia em escala mundial. A ditadura chilena impunha uma severa restrição para servir como exemplo, em especial, para os países desenvolvidos. Para isso era necessária a sua incorporação nas políticas públicas por governos eleitos em países democráticos. A eleição de Thatcher na Inglaterra e Reagan nos Estados Unidos possibilitou a legitimidade política e a força econômica e financeira para impor a desregulamentação dos mercados, principalmente dos mercados de capitais e financeiros. Legitimou, também, a privatização dos serviços públicos e empresas estatais, o enxugamento dos orçamentos públicos e a transformação das políticas públicas - a universalização dos direitos de cidadania - em políticas focadas para a redução das carências específicas das populações mais pobres. Um ataque direto às políticas de bem-estar social construídas, em especial na Europa, a partir do fim da Segunda Guerra Mundial, para enfrentar a pressão do movimento social organizado e o desafio do comunismo.

O Estado de bem-estar social democrata na Europa ou "liberal" nos Estados Unidos tinha que sofrer uma radical transformação em sua natureza republicana e cidadã. O Estado neoliberal que surge dessa nova hegemonia política tem como características centrais a garantia dos direitos individuais e de propriedade e as instituições para a liberdade dos mercados. Na conceituação de Harvey (2008:75):

"São aos arranjos institucionais essenciais à garantia das liberdades individuais. $\mathrm{O}$ arcabouço legal disso são obrigações contratuais livremente negociadas entre indivíduos juridicamente configurados no âmbito do mercado. A santidade dos contratos e o direito individual à liberdade de ação, de expressão e de escolha têm de ser protegidos. O Estado tem, portanto, de usar seu monopólio dos meios de violência para preservar a todo custo essas liberdades. Por extensão, considera-se um bem fundamental a liberdade de negócios e corporações (vistos legalmente como indivíduos) de operar nesse arcabouço institucional de livres mercados e livre comércio. A 
empresa privada e a iniciativa dos empreendedores são julgadas as chaves da inovação e da criação de riqueza. Protegem-se os diretos da propriedade intelectual a fim de estimular as mudanças tecnológicas. Assim, os contínuos aumentos da produtividade devem proporcionar padrões mais elevados a todos."

Essa nova natureza do Estado garante a liberdade individual no mercado e transforma o cidadão em consumidor, na medida em este é o responsável individual pelo seu fracasso ou sucesso e pelo seu próprio bem-estar. O sucesso e o fracasso são o resultado das virtudes empreendedoras ou da falta delas. O exemplo mais marcante é não investir o suficiente em seu próprio capital humano por meio da educação e a atribuição da culpa do desemprego ao desempregado por não aceitar um salário menor ou os trabalhos existentes. Esse princípio é aplicado ao bem-estar social, à educação, à saúde e aos regimes previdenciários. A solidariedade republicana entre a esfera pública e o cidadão deixa de existir, a não ser para garantir os direitos individuais de propriedade mesmo que para isso tenha que apelar para o poder policial do Estado.

O neoliberalismo introduz em sua concepção uma enorme desconfiança em relação à democracia. A autonomia do regime popular e democrático é considerada uma ameaça potencial aos direitos e liberdades individuais inscritas na constituição. ${ }^{2}$ A democracia é risco que só é possível em sociedades ricas e com uma forte classe média, para garantir a estabilidade política. Isso implica um executivo e um judiciário fortes, poderes mais ligados à razão técnica, do que um legislativo mais transparente e dependente da legitimidade democrática. A governança institucional, portanto, deve ficar na mão dos especialistas e elites técnicas; governa a ordem executiva (Medidas Provisórias) e por decisão judicial preferencialmente à tomada de decisões democrática e legislativa. Algumas instituições-chave devem estar sob controle técnico e não democrático, como o Banco Central, e o conflito político deve ser arbitrado pelos tribunais. O sistema legal e não o parlamento deve ser a última instância de resolução dos conflitos.

\footnotetext{
${ }^{2}$ Existe uma ampla literatura sobre a diferença entre os regimes liberais e democráticos. Os neoliberais e os liberais conservadores os consideram idênticos. Os democratas progressistas e socialistas os diferenciam exatamente pela autonomia dos cidadãos em seu processo de luta para ampliação dos seus direitos universais. A referência básica para a diferença entre liberdade individual baseada no mercado versus a democrática é Polanyi (2000). A defesa da concepção liberal está em Tocqueville (1977).
} 
A livre mobilidade do capital entre países, regiões e cidades é decisiva para a melhoria das condições de vida e diminuição das desigualdades entre os países dentro das suas fronteiras. As barreiras às livres movimentações devem ser removidas, exceto aquelas ligadas ao interesse nacional. ${ }^{3}$ Os Estados nacionais não devem exercer soberania sobre os movimentos de mercadorias e de capital que devem ser regulados pelo mercado global. Assim, a competição internacional melhora a eficiência e a produtividade, reduz os preços e a inflação.

Essa noção da competição internacional como deflagradora dos processos de melhoria da produtividade tem forte impacto nas cidades e regiões metropolitanas que passam a ser vistas como competidoras por atração de recursos globais.

O objetivo central do artigo é discutir o impacto dessa ideologia hegemônica na transformação urbana que está ocorrendo na cidade do Rio de Janeiro. Na próxima parte será analisada a relação da cidade com a acumulação capitalista. Em seguida será discutido o papel dos investimentos nos megaeventos, Copa do Mundo e Jogos Olímpicos, em relação à diminuição das desigualdades e acesso aos serviços públicos. Por último, algumas conclusões serão apresentadas sobre o legado dos megaeventos.

\section{A cidade como lócus da acumulação capitalista}

A cidade é um espaço da luta pelos direitos sociais - luta pelo direito à moradia, à saúde, ao transporte, aos salários dignos e à melhoria das condições de vida social. A questão urbana é uma das principais áreas de lutas políticas e sociais pelos direitos de cidadania, especialmente das classes menos favorecidas. A história da urbanização corre em paralelo com a história da luta de classes e pelos espaços urbanos. Os exemplos marcantes dessas lutas são a Comuna de Paris de 1871, o maio de 1968 e os movimentos sociais urbanos contemporâneos em Paris, em Londres, no Cairo, em Istambul e, mais recentemente, no Rio de Janeiro e São Paulo. As causas deles são diferentes, mas conjugam do mesmo espaço de manifestação: o urbano. Essas manifestações marcam os espaços dos poderes dos grupos assalariados no enfrentamento com os projetos de urbanização das classes dominantes.

\footnotetext{
${ }^{3}$ Os recentes vazamentos de informações sobre a vigilância da ligações telefônicas e da internet pelas agências de segurança dos Estados Unidos mostram bem a contradição do neoliberalismo.
} 
A reforma de Paris no século XIX ficou famosa como modelo para outras cidades modernas do mundo. Foi liderada pelo Barão Haussmann no período de Napoleão III e tinha como objetivo central uma cidade mais segura, avenidas e ruas com maior visibilidade, saneamento e habitação melhores, e maior espaço para a circulação de mercadorias e para o comércio de lojas. O maior espaço de circulação também propiciava o acesso mais rápido da polícia e das forças de segurança dificultando a construção de barricadas durante os protestos populares ruas.

O efeito simbólico dessa reforma estava em criar uma nova atmosfera social, política e cultural com visão dos espaços abertos e luminosidade da cidade, ${ }^{4}$ o que alterou quase $60 \%$ do seu espaço. Não era apenas a realização de melhorias pontuais que somadas individualmente passassem a nova ideia urbana. Ao contrário, a dimensão totalizante da integração do espaço e do tempo urbano foi pensada para criar a dimensão urbana da burguesia triunfante e do potencial do capitalismo francês no século XIX.

O pós-modernismo está marcado pela fragmentação, indeterminação e desconfiança dos discursos universais modernistas (Harvey, 2007). Essa fragmentação e relativização passam a dar força explicativa para condições específicas e pontuais na política pública e para a predominância da individualização nos processos sociais.

As condições de vida nas cidades e áreas urbanas representam situações configuradas pelas diferentes formas do modo de produção capitalista. O que acontece nas cidades é o espaço decisivo da estruturação do capital e da ação das classes sociais (Harvey, 2008). A urbanização, a globalização, os conflitos e a dinâmica da luta de classes não podem ser entendidos sem a compreensão do movimento dinâmico do capital ao nível global.

A financeirização do mundo provocou, nas últimas décadas, a intensificação da concentração e centralização dos capitais. Uma das áreas que mais tem sido utilizadas como lastro dessa intensificação da concentração e centralização dos capitais é a dos ativos relacionados com a propriedade da terra (urbana e rural), das rendas derivadas desses ativos. Essa característica do ciclo mais recente de valorização do capital, que levou para a crise do "sub prime", aproximou ainda mais os rentistas e os financistas.

Essa aproximação recente não é uma novidade. Na fase de acumulação primitiva do capital, séculos XVI e XVII, a acumulação de riqueza pela burguesia emergente foi baseada de forma importante nos ativos de terra. Em outras épocas a propriedade da

\footnotetext{
${ }^{4}$ Também conhecida como "Paris cidade luz".
} 
terra permaneceu como fonte primordial de reserva de valor de acumulação de riqueza. Hoje em dia, mesmo com todo o predomínio da indústria e das finanças, as maiores fortunas do mundo não dispensam o controle da terra.

A especulação com os ativos de terras nas áreas urbanas fornece um escoadouro importante para a acumulação do capital. A importância do tempo de retorno do investimento do capital mais rápido nessa área do que em outras garante uma aceleração do ganho superior aos demais, integrando essa área na lógica do capital financeiro.

A desregulamentação dos mercados ou a sua autorregulação levou a uma aceleração da criação de instrumentos financeiros que buscavam os ganhos muito rápidos e a incorporação de grupos de renda mais baixa ao esquema de aquisição de ativos de propriedade de terra e moradia fortemente acoplado ao mecanismo de mitigação de risco.

Esse processo gera um desenvolvimento urbano desigual e com localização espacial de diferentes relações de poder (hegemônicas) entre diferentes grupos que vão gerar conflitos que serão decisivos para o destino da democracia.

No caso dos Jogos Olímpicos do Rio de Janeiro, a dominância da lógica financeira especulativa explica a escolha da Barra da Tijuca como o centro dos investimentos, ao contrário de Londres onde as instalações (12) se concentraram ao leste da cidade. Trata-se de uma área onde água e solo foram contaminados por quatro séculos de uso sem cuidado pela indústria têxtil e refinarias e é ocupada hoje por imigrantes de baixa renda. Formaram-se comitês com participação da comunidade e, ao se descobrir que não haveria demanda por parte das instalações após os Jogos, sedes permanentes foram convertidas em provisórias. Por outro lado, houve investimento em infraestrutura para benefício da vizinhança, e o planejamento se estendeu para além de 2012, ano das Olimpíadas de Londres.

\section{O legado dos megaeventos}

A Federação Internacional de Futebol Associado (FIFA) e o Comitê Olímpico Internacional (COI) detêm o monopólio dos direitos de exploração das imagens e das receitas dos principais megaeventos esportivos mundiais. Esses eventos são as suas 
principais fontes de receitas e formam a base para a formulação dos seus planos de marketing e a garantia para os seus patrocinadores. ${ }^{5}$

Esse monopólio e as regras contratuais daí derivadas que os países e cidades que vão sediar esses eventos assinam são praticamente uma intervenção branca na legislação nacional. Todos os direitos que entram em conflito com as garantias legais assumidas pela FIFA e pelo COI com os seus patrocinadores passam em substituição à legislação local. Os países e os governos regionais têm que alterar a sua legislação para adaptá-la aos requisitos legais do contrato assinado e assumir os possíveis riscos dos prejuízos futuros. A FIFA e o COI recebem bilhões de dólares, principalmente das televisões, e não pagam pelas instalações esportivas, infraestrutura, segurança etc. dos eventos. A África do Sul recebeu US\$ 500,0 milhões como participação nas receitas da Copa do Mundo. A FIFA aproximadamente US\$ 3,0 bilhões. ${ }^{6}$

Tanto a FIFA quanto o COI são entidades autocráticas dominadas pelo eurocentrismo. Existe uma enorme concentração de poder e número ilimitado de reeleições dos seus dirigentes máximos. Essa autocracia não convive bem com as democracias, como ficou mostrado nas manifestações dos seus dirigentes com relação ao andamento das obras nos estádios brasileiros.

O eurocentrismo faz com que todas as especificações técnicas dos estádios, arenas e instalações esportivas tenham como parâmetros a realidade econômica e social dos países desenvolvidos. Esses países já contam com toda rede de infraestrutura de serviços públicos construída e, em muitos casos, de estádios e instalações esportivas. Apenas alguns ajustes necessitariam ser feitos. A renda per capita também torna acessível para grande parte da população os ingressos para as competições esportivas, que de modo geral já são realizadas nesses países.

\footnotetext{
${ }^{5}$ A estimativa é de que aproximadamente $90 \%$ das receitas da FIFA e do COI dependem diretamente dos megaeventos.

${ }^{6}$ A estimativa da FIFA quanto ao Mundial de 2014 para receita de direitos de transmissão, patrocínio e licenciamentos chega a cerca de $\mathrm{R} \$ 10$ bilhões, $36 \%$ maior que o faturamento com a Copa do Mundo da África do Sul, em 2010, e 110\% superior ao da Alemanha, em 2006. Os direitos de transmissão são a maior fonte de receita da FIFA, seguidos pelo patrocínio. Para a Copa do Mundo de 2014, a entidade conta com o apoio de 20 empresas para promover o evento. Fonte: http://esportes.r7.com/futebol/noticias/fifa-vai-ter-lucro-de-r-10-bilhoes-com-copa-do-mundo20130327.html (Acesso em 25/06/2013 às 11:42).
} 
O atrativo dos países em desenvolvimento para sediar esses eventos residiria na possibilidade de aproveitar e oportunidade e realizar os investimentos em serviços públicos que teriam que ser feitos de qualquer maneira.

O problema que surge com essa forma de pensar o desenvolvimento urbano com o aproveitamento dos megaeventos é saber se o resultado será uma "cidade para os megaeventos" ou os "megaeventos para a cidade". É importante lembrar que uma cidade que não fornece serviços públicos decentes para os seus habitantes não os fornecerá para os visitantes, independente das suas belezas naturais.

Como apresentado na primeira parte deste artigo, a ideologia neoliberal hegemônica teve enorme influência em definir os contornos do urbano na nova etapa da globalização como uma disputa entre as cidades pelos recursos globais. Daí a disputa cada vez mais acirrada, para gáudio das entidades esportivas internacionais, pelo direito de sediar os grandes eventos esportivos. A estratégia das cidades passa a ser se preparar para os eventos esportivos e não se estruturar para um desenvolvimento urbano destinado a atender os direitos sociais pela melhoria dos serviços públicos universais.

O exemplo do Rio de Janeiro é paradigmático dessa estratégia. O relatório apresentado pelo Comitê Olímpico Brasileiro (COB) recebeu a nota mais baixa entre os finalistas: 6,8. Em primeiro lugar, ficou Tóquio, com 8,6. Depois, vieram Madri $(8,4)$ e Chicago $(7,4)$. O Rio, na verdade, foi o quinto colocado na disputa, ficando atrás ainda de Doha, no Catar, que teve nota 7,4. A cidade, no entanto, foi eliminada, já que só poderia realizar o evento no mês de outubro, data considerada inadequada pelo Comitê Olímpico Internacional (COI). Ficaram de fora Praga, na República Tcheca, e Baku, no Azerbaijão. ${ }^{7}$ Isso mostra a péssima qualidade do projeto olímpico do Rio de Janeiro.

A estratégia da "cidade para os megaeventos" busca melhorias pontuais para os serviços públicos que não resolvem os problemas estruturais. A implantação do sistema de "Bus Rapid Transport - BRT" e "Bus Rapid Service - BRS"8 são exemplos dos alívios temporários e pontuais, em um sistema que já se encontra operando acima do seu limite operacional. Dadas as suas especificações técnicas, eles oferecem pouca margem para crescimento. São mais do mesmo. E atendem aos interesses das empresas de ônibus, que prestam um péssimo serviço, sem que os órgãos reguladores estaduais e municipais se manifestem.

\footnotetext{
${ }^{7}$ Folha de São Paulo. RIO 2016. Caderno Esporte, 05/06/2008.

${ }^{8} \mathrm{O}$ interessante é o nome em inglês. Será que é para conferir credibilidade e segurança? Prefiro achar que é subserviência cultural mesmo.
} 
Outro problema é incorporar novas áreas urbanas, independente das características ambientais, ${ }^{9}$ e sem serviços públicos adequados, o que serve apenas para a aceleração da acumulação do capital imobiliário. Por que não investir na melhoria operacional da Supervia? Por que não implantar o metrô de superfície usando as linhas e traçados já existentes? Isso possibilitaria integração do modal rodoviário e ferroviário, expandindo este último.

Em termos de tecnologia e inovação na área de transporte público urbano, o modal rodoviário é o que tende a perder maior relevância. A utilização de veículo leve sobre trilho-VLT e monotrilhos tende a ser a solução mais eficiente e amigável ambientalmente.

A parceria, porém, entre o transporte rodoviário privado e o capital imobiliário domina a ocupação do espaço urbano na cidade do Rio de Janeiro e nas demais cidades. O interesse do capital imobiliário determina a prioridade da ocupação urbana e a população que se vire com os serviços públicos. A pressão advinda dessa ocupação leva os empresários de ônibus e vans a atender a demanda. Ao invés do planejamento urbano público, é o processo especulativo sobre a ocupação do solo urbano que prioriza a oferta do serviço público necessário. Esse processo degrada o espaço urbano pela ocupação informal, deteriora o meio ambiente local e fragmenta a cidade.

O legado principal da realização dos megaeventos deveria ser a modernização da malha viária, investimento nos aeroportos e na modernização do sistema de trens urbanos e metrô, dotando a cidade de uma infraestrutura de transporte público confortável, confiável e eficiente. As 12 principais regiões metropolitanas brasileiras, nas quais aproximadamente 13 milhões de pessoas se deslocam diariamente entre os municípios que as constituem, não suportam mais deslocamentos baseados majoritariamente no modal rodoviário (ônibus e automóveis).

Entre 1977 e 2005, ocorreu uma mudança nas grandes regiões metropolitanas do Brasil com a queda no uso do transporte público de $68 \%$ para $51 \%$ do total de viagens motorizadas e o aumento no uso do automóvel de 32\% para 49\% (IPEA, 2011). Isso gerou enormes consequências: maiores gastos dos usuários, aumento do consumo de energia e geração de externalidades negativas como poluição, congestionamentos e acidentes de trânsito. O tempo de deslocamento casa-trabalho no Brasil, no período que vai de1992 a 2009, aponta que trabalhadores de baixa renda no país fazem viagens, em

\footnotetext{
${ }^{9}$ A região de Guaratiba é um ecosistema bastante frágil.
} 
média, 20\% mais longas do que os mais ricos (IPEA, 2011). Na cidade do Rio de Janeiro as viagens de automóvel já superam em quantidade as viagens de ônibus (IPEA, 2011).

A crise de mobilidade urbana é causada, principalmente, pela falta de planejamento do poder público e pela opção preferencial pelo transporte individual em detrimento do transporte público. Os incentivos fiscais concedidos pelo governo federal para a indústria automobilística também contribuíram para o aumento das vendas junto com a maior facilidade de crédito, tanto em termos de custo quanto pelo aumento dos prazos de amortização e pelo aumento do poder aquisitivo da população. Esses fatores levaram a um aumento expressivo do número de automóveis, muito superior ao investimento em vias públicas e na elaboração e implantação de modais alternativos de transporte público. O deslocamento urbano se transformou em um martírio através de longas distâncias, engarrafamentos e as constantes panes do sistema público de transporte. Além disso, o custo do tempo perdido nos engarrafamentos se eleva exponencialmente não só do ponto de vista individual, mas principalmente social com o aumento da violência, do estresse e da ausência ao trabalho. Na cidade do Rio de Janeiro a mobilidade urbana tem piorado de forma acentuada. O tempo de deslocamento já se iguala ao da cidade de São Paulo. ${ }^{10}$

Essa opção preferencial pelo transporte rodoviário que marcou o processo de modernização urbana ${ }^{11}$ até os anos sessenta do século passado refletia basicamente a visão modernista de adaptar a cidade a sua época. No Brasil, Brasília representa o urbanismo modernista em uma das suas versões mais elaboradas.

No Rio de Janeiro o "Plano Piloto para a Baixada de Jacarepaguá" - mais conhecido como "Plano Lucio Costa', seu autor, o mesmo do plano piloto de Brasília foi o projeto que teve maior repercussão para o desenvolvimento urbano do Rio. Tal plano piloto também privilegiou o transporte rodoviário e o uso intensivo do automóvel particular. A partir daí, outras intervenções viárias foram feitas para adequar a cidade ao aumento do número de veículos, porém sempre aquém da necessidade.

\footnotetext{
${ }^{10}$ O Globo, Transporte de $1^{\mathrm{a}} \ldots$ marcha $17 / 03 / 2013$.

11 O processo "suburbanização" das cidades americanas é baseado na utilização intensiva do automóvel, com os combustíveis fósseis baratos, marca inconfundível dos anos de ouro da hegemonia americana. Na década de setenta do século XX esse modelo começa a fazer água, com a desvinculação do dólar em relação ao ouro (1971), com a elevação dos preços do petróleo (1973 e 1978), a elevação dos juros básicos americanos (1978) e reconstrução das economias europeias, em especial a alemã, e a japonesa, que passaram a produzir automóveis mais modernos e eficientes.
} 
O principal resultado dessas intervenções urbanas pautadas pela lógica do transporte rodoviário é a transformação de determinados bairros em bairros de passagem - com a sua consequente degradação, perda da qualidade de vida das pessoas e da sua inserção social local -, assim como os engarrafamentos frequentes nos deslocamentos entre o local de residência e o trabalho.

Essa lógica de desenvolvimento urbano necessita sempre da ampliação de novos espaços urbanos que são ocupados sem o necessário planejamento da implantação dos serviços públicos. Dado o montante dos investimentos que são necessários para a implantação desses sistemas, a boa teoria e prática dos investimentos em serviços públicos indica que eles têm que ser realizados na frente da demanda e com boa margem de capacidade a ser ocupada. Deve também obedecer à lógica do adensamento urbano para usufruir das economias de escala e escopo do investimento. Se não houver planejamento desses investimentos a ocupação urbana vai ser desordenada e os serviços públicos serão de má qualidade.

Esse tem sido o padrão recorrente de desenvolvimento urbano na cidade do Rio de Janeiro. Abre-se uma nova área de expansão urbana, não se planeja a implantação dos serviços públicos, transporte, moradia, saneamento etc.. A indústria de construção civil começa a ocupar o novo espaço, aumenta-se a demanda por serviços de mão-deobra e, na ausência de um sistema de transporte rápido, eficiente e confortável, os trabalhadores do setor de serviços se deslocam para lá, constroem suas casas em terrenos dos quais não possuem a propriedade e não são servidos por serviços públicos. As favelas proliferam e se tornam uma inovação institucional das pessoas para sobreviverem nesse ambiente hostil.

O legado deixado pelos equipamentos construídos por ocasião dos jogos, na maioria dos casos, é uma infraestrutura cara e monumental para o evento, mas passado este, dificilmente encontra-se um uso que justifique seu custo de construção e operação. Exemplo recente é o parque aquático dos Jogos de Pequim, que foi transformado numa piscina pública. Os estádios muitas vezes continuam a ser usados, mas raramente ocupam a sua capacidade, tornando-se "elefantes brancos" com altos custos de manutenção em países com renda per capita inferior aos dos desenvolvidos para onde eles foram projetados. Apesar de se argumentar que a construção de equipamentos pode revitalizar áreas degradadas, isso precisa ser feito levando em conta a paisagem urbana e sua integração com as construções olímpicas. O Estádio Ninho do Pássaro, em Beijing, 
foi construído cercado por um grande parque e servido pela rede de metrô. Esse parque, hoje em dia, é pouquíssimo frequentado, assim como o estádio. Na África do Sul, estádios foram construídos em meio a vias expressas automotivas, longe de centros residenciais ou comerciais, tornando-se igualmente abandonados em seus entornos após os jogos.

Um argumento frequentemente usado a favor da realização de megaeventos é o fato de que eles promovem uma maciça exposição midiática das suas sedes em um curto período, o que poderia fazer com que turistas e investidores fossem atraídos para dar sustentabilidade no longo prazo. Esse argumento, no entanto, é controverso. Em muitos casos, como Londres e Paris, a cidade já está no "mapa" internacional. Em outros, ela não teria como se beneficiar da exposição internacional por ter pouca vocação para o turismo, como no caso de Atlanta. O caso paradigmático é Barcelona. Mas teria o Rio de Janeiro condições políticas de reproduzir Barcelona?

As firmas de consultoria, muitas delas parceiras do COI e da FIFA, costumam projetar benefícios econômicos de curto e longo prazos para os locais-sede, sejam países ou cidades como um todo. Pelo lado estritamente econômico, a maioria dos estudos realizados nos últimos 15 anos sobre os impactos econômicos dos megaeventos não é encorajadora. A renda gerada pelos megaeventos seria ínfima se comparada ao PIB nacional. Assim, as análises que enfatizam o impacto dos megaeventos na economia nacional normalmente não costumam ser acuradas (Hagn e Maennig, 2008 e 2009; Humphreys e Zimbalist, 2008; Jasmand e Maennig, 2008 e Zimbalist, 2010). Aqui aqui

No curto prazo, o aumento do investimento em infraestrutura por empreiteiras e construtoras não necessariamente gera um aumento significativo do emprego, devido principalmente ao efeito de realocação de mão-de-obra já empregada e não criação de emprego. Além disso, se promovido por meio de aumento do déficit público, conseguirse-ia apenas um aumento de emprego no curto prazo, acompanhado de uma inflação nos salários e nos aluguéis. A criação de empregos não está descartada, ela é possível, mas não é garantida.

$\mathrm{Na}$ análise de longo prazo, os estudos mostram que as fontes de renda geradas pelos megaeventos normalmente cobrem os custos diretamente envolvidos com a sua preparação. Assim, o que restaria seriam os aumentos no turismo e comércio, bem como o desenvolvimento da infraestrutura. As estimativas referentes a número de turistas, por exemplo, utilizam o número de visitantes decorrente do evento como uma variável 
completamente independente do resto das pessoas que visitam a cidade em outros períodos, desconsiderando o efeito "crowding out" frequente durante os jogos. Um exemplo claro disso foi o fato de que, durante as Olimpíadas de 2012 em Londres, o distrito dos teatros de West End ficou anormalmente esvaziado. Quanto aos argumentos relacionados ao turismo, os resultados também são inconclusivos. Os exemplos de Salt Lake City, Atlanta, Pequim e Londres indicariam a existência de um crowding out effect durante os eventos. Haveria a substituição de turistas tradicionais por aqueles animados pelos megaeventos. O ganho bruto de visitantes raramente se altera de maneira significativa, como ilustrado pelos casos de Beijing 2008 (onde o número foi pouco diferente daquele do mesmo período no ano anterior) e da África do Sul durante a Copa do Mundo (onde o ganho bruto de chegadas internacionais não foi muito além de 100.000, quando as consultorias haviam inicialmente previsto 500.000 (Matheson, 2009).

Até os anos 1990, os Jogos Olímpicos e as Copas do Mundo concentravam-se eminentemente em países desenvolvidos ocidentais, com algumas exceções. O que se nota a partir de então é uma predominância crescente de países emergentes. Essa transferência dos megaeventos tem um duplo sentido. No processo de crescimento econômico, os países menos desenvolvidos passam a apresentar candidaturas ao COI e à FIFA, como forma do reconhecimento da sua ascensão a um patamar internacional, enquanto essas organizações vêm se tornando cada vez mais abertas a essas candidaturas. Essa tendência, em outro sentido, estaria sendo estimulada, ao menos em parte, pelos países desenvolvidos, que não mais desejam arcar com os custos de sediar eventos. A FIFA e o Comitê Olímpico Internacional, ao priorizarem candidaturas emergentes, escolhem países com carência de investimentos em infraestrutura, que usam a realização desses investimentos como forma de tornar mais atrativos os encargos dos megaeventos.

Este tema é controverso. Dadas as características monopolistas da FIFA e do COI, estes não estariam muito interessados com a localização, mas sim, com os lucros. A Copa do Mundo da África do Sul é um bom exemplo de qual é a preocupação central da FIFA. O que se pode afirmar com segurança é que, para os EUA e para a Europa, a Copa do Mundo e os Jogos Olímpicos não são mais megaeventos interessantes.

Entretanto, um aspecto importante do legado de longo prazo dos megaeventos é a política pública para o desenvolvimento do esporte. A democratização do acesso da 
população à prática esportiva (educação física) é um direito fundamental da construção da cidadania.

Se definirmos a atividade física como uma forma de conhecimento do mundo através do relacionamento do corpo com a realidade exterior, ela se transforma em um forte vínculo entre o indivíduo e o seu meio social. É um fator de civilidade extremamente importante. Ensina regras de convivência social e permite um claro reconhecimento dos limites individuais e sociais. Ensina a conhecer a si, o outro e os outros, no sentido de que a existência precede a essência, isto é, a consciência não é algo distinto do corpo.

O lazer esportivo se enquadra perfeitamente neste conceito de autoconhecimento e conhecimento dos outros. O que estamos tentando mostrar é que existe uma continuidade entre as atividades com mais alta tolerância ao erro, isto é, onde o lazer e o divertimento predominam, e as atividades com mais baixa tolerância ao erro, onde a competição e a excelência da performance predominam. A primeira é lazer esportivo. A segunda o esporte profissional.

Essas condições de prática da atividade esportiva, seja por lazer, seja profissionalmente, constituem o locus privilegiado da ação humana nessa área. Arrumar o campo de pelada significa local e hora. Além disso, permite que uma série de serviços secundários ao serviço principal - local, hora, bola, uniforme e escalar os times - sejam organizados para a completa realização do lazer: o vendedor de refrigerante e cerveja, o pagode, o churrasquinho etc...

Podemos comparar essa precária prestação de serviços, com a sofisticada cadeia da produção do espetáculo esportivo: treinamento, assistência médica, alimentação regulada, campo bem tratado, concentração em hotéis, uniformes com materiais especiais, estádios com infraestrutura de alimentação, estacionamento, lugares marcados etc...

Estamos lidando em ambos os casos com a mesma cadeia de produção, variando apenas a sua complexidade e sofisticação. Isto não quer dizer que este seja um problema trivial. A diferença entre o amadorismo e o profissionalismo é grande. O que os une é a paixão pela atividade que está sendo realizada. Não existe esporte sem torcida apaixonada, da mesma forma que o lazer só se organiza pela paixão dos seus praticantes. 
Portanto, existe um misto de criatividade e de necessidade de legitimação por parte da sociedade para que as atividades esportivas de lazer passem a subir na escala da valorização social das suas atividades.

Essa rede de interesses econômicos e de negócios, a interação de vários mercados e áreas de investimento e a sua integração em uma única direção - a valorização do espetáculo esportivo e do ídolo esportivo - fornecem o impulso crucial para a sua contínua reprodução: a expectativa de ascensão social para as populações mais carentes. O sonho de se tornar um ídolo os anima a investir em estratégias de sobrevivência, que possam lhes dar um espaço de valorização social, mesmo que local, para que consigam reproduzir em seu universo algo da magia da vida dos seus grandes ídolos.

Por último, porém não menos importante, cabe registrar a necessidade de uma política direcionada para o aproveitamento da infraestrutura esportiva construída, para evitar que eles se transformem em elefantes brancos. Em países de baixa ou média renda per capita, é difícil que se encontrem as condições de sustentabilidade econômica e financeira das arenas e estádios construídos para os Jogos Olímpicos e a Copa do Mundo. Estes são projetados para a realidade dos países desenvolvidos e incorporam nos seus projetos de engenharia as condições econômicas e sociais desses países, o que encarece sobremaneira a sua manutenção em países mais pobres.

Até o momento não se conhece uma política pública estruturante para o esporte e a atividade física, nem para o uso após os megaeventos das instalações esportivas construídas.

\section{Conclusão}

As Olimpíadas em Londres estão sendo consideradas como um segundo caso de sucesso. No entanto, este sucesso é em grande parte fruto da infraestrutura que já estava montada há décadas. Para os países emergentes, os Jogos Olímpicos trazem o desafio e a oportunidade de "reestruturar a estrutura" para o desenvolvimento urbano, econômico e social. O legado dos megaeventos deve ser avaliado em termos de aspectos econômicos, materiais, urbanos, políticos e simbólicos. Os legados políticos, simbólicos e espaciais são provavelmente os mais tangíveis, duradouros e significativos. No capitalismo, dado o seu caráter de classe, os resultados do capital investido são 
desigualmente distribuídos. Como os projetos da Copa do Mundo e dos Jogos Olímpicos reproduzem as condições da dominação hegemônica sobre o espaço urbano, o legado também as manterá.

As instalações esportivas dos megaeventos no Brasil, em muitos locais, vão se transformar em "elefantes brancos" após os eventos, sendo subutilizados e necessitando de altas taxas de manutenção, pois não estão enraizadas em planos de desenvolvimento metropolitano, como no caso de Barcelona. Este foi um exemplo de única possibilidade dos megaeventos serem positivos - uma oportunidade de superar gargalos políticos e acelerar o desenvolvimento.

O segundo ponto é a falta de estrutura esportiva no país. Este impacto também é importante, pois parte do ponto de vista de como democratizar o esporte e a prática esportiva. É importante avaliar a diferença entre países que têm estrutura esportiva organizada e aqueles que não têm. Há enormes complicações políticas na organização do esporte no Brasil. Estes são problemas importantes para mostrar diferenças entre realidades dos países e questionar os impactos do evento no esporte, sendo que no caso brasileiro há poucos esportes organizados e bem articulados.

Essa é a importância de atentar para os pontos mencionados anteriormente: as diferenças dos países e seus impactos - no Brasil, impactos serão maiores em termos regionais - e a questão da organização do esporte. Quais serão os impactos na organização do esporte após os eventos?

O simbolismo dos megaeventos, o legado intangível dos megaeventos para o Brasil e o Rio de Janeiro, que não estão na geografia global do poder monopolístico da FIFA ou do COI, dificultam que se consiga furar esses grandes interesses econômicos estabelecidos e dar a sustentabilidade de longo prazo derivada da exposição da imagem. Eles foram criados para estrutura de países desenvolvidos, o que não quer dizer ressalte-se - que não devem ser realizados aqui. O simbolismo sustentável já está naturalmente inserido em Londres, Paris, Berlim e Nova Iorque pela posição que estas cidades ocupam na história do capitalismo hegemônico.

O não entendimento dessas limitações simbólicas, políticas e institucionais de sediar os Jogos Olímpicos e a Copa do Mundo reflete a opção estratégica da cidade para os megaeventos e não dos megaeventos para a cidade. 
O único efeito positivo incontestável seria o orgulho cívico e a felicidade geral catalisada pelo evento. Nisso o Rio de Janeiro se configura por sua história e pelo caráter do seu povo como imbatível. Resta saber se a festa será maior que a ressaca.

\section{Referências bibliográficas}

HAGN, F.; MAENNIG, W. Large Sport Events and Unemployment: The Case of the 2006 Soccer World Cup in Germany, Applied Economics, Vol. 410, n. 25, pp. 3295-302, 2009.

- Employment Effects of the Football World Cup 1974 in Germany, Labour Economics, Vol. 15, n. 5, pp. 1062-75, 2008.

HARVEY, D. O neoliberalismo, história e implicações. Edições Loyola: São Paulo, 2008.

—. A Condição Pós Moderna. 6. ed. Edições Loyola: São Paulo, 2007.

HUMPHREYS, B.; ZIMBALIST, A. The Financing and Economic Impact of the Olympic Games. In: HUMPHREYS, Brad; HOWARD, Dennis. (eds.). The Business of Sports. Vol. 1. Westport, Connecticut: Praeger, 2008.

IPEA. Infraestrutura Social e Urbana no Brasil subsídios para uma agenda de pesquisa e formulação de políticas públicas A mobilidade urbana no Brasil. Comunicados do IPEA número 94. Brasília: Maio de 2011.

JASMAND, S.; Maennig, W. Regional Income and Employment Effects of the1972, Munich Summer Olympic Games, Regional Studies, Vol. 42, n. 7, pp. 991-1002, August, 2008.

MATHESON, V. Economic Multipliers and Mega-Event Analysis, International Journal of Sport Finance, Vol. 4, n. 1, pp. 63-70, 2009.

POLANYI, K. A Grande Transformação. As origens da nossa época. Rio de Janeiro: Campus, 2000.

TOCQUEVILlE, A. A Democracia na América. São Paulo: ED. Da Universidade de São Paulo, 1977.

ZIMBALIST, A. Is It Worth It? Finance \& Development, pp. 9-1, March, 2010. 